\title{
Evaluation the Acute Effects of Hyperbaric Oxygen Therapy on Eye Anterior Segment Morphology and on İntraocular Pressure
}

Fatih Akıncı ( $\nabla$ drakincifatih@gmail.com )

Erzurum Bolge Egitim ve Arastirma Hastanesi https://orcid.org/0000-0002-1218-8544

Abdullah Arslan

Necmettin Erbakan University Meram Faculty of Medicine: Necmettin Erbakan Universitesi Meram Tip Fakultesi

Muammer Özcimen

Necmettin Erbakan University Meram Faculty of Medicine: Necmettin Erbakan Universitesi Meram Tip Fakultesi

\section{Research Article}

Keywords: hyperbaric oxygen therapy, eye anterior segment morphology , intraocular pressure

Posted Date: June 7th, 2021

DOl: https://doi.org/10.21203/rs.3.rs-528769/v1

License: (c) (i) This work is licensed under a Creative Commons Attribution 4.0 International License. Read Full License 


\section{Abstract}

Purpose: In this study the acute effects of 1 session of hyperbaric oxygen therapy on eye anterior segment morphology and on intraocular pressure was evaluated.

Materials and methods: 30 patients taking hyperbaric oxygen therapy for different indications were included in this prospective study. Only the right eye per patient was included in the study. The refractive errors were measured with autorefractometry, intraocular pressures were measured with pneumatic tonometry; anterior segment parameters pachymetry, keratometry, anterior chamber depth and iridocorneal angle values were measured with corneal topography prior to and 24 hours after 1 session of hyperbaric oxygen therapy.

Results: In this study 30 eyes from a total of 30 patients were evaluated; 19 men (\% 64) and 11 women (\% 36). Median age was $44.33 \pm 16.12$ (Age range 18-80 years). Mean intraocular pressure was $13.7 \pm 4,16$ $\mathrm{mmHg}$ (milimetermercuries), mean central corneal thickness was $531.9 \pm 28.24 \mu \mathrm{m}$, mean anterior chamber depth was $3.30 \pm 0.375 \mathrm{~mm}$, mean iridocorneal angle value was $35.3 \pm 6.61$ degrees before hyperbaric oxygen therapy. The mean intraocular pressure was $12.66 \pm 4,54 \mathrm{mmHg}$, mean central corneal thickness was $529.43 \pm 26.68 \mu \mathrm{m}$, mean anterior chamber depth was $3.28 \pm 0.372 \mathrm{~mm}$, mean iridocorneal angle value was $34.5 \pm 6.42$ degrees after HBOT. A statistically significant decrease in these values were recorded. No statistically significant changes were found in spheric equivalent and keratometry values of the patients before and after HBOT.

Conclusions: After one session of HBOT a decrease in intraocular pressure, central corneal thickness, anterior chamber depth and iridocorneal angles of patients were observed; keratometry and spheric equivalent values remained unchanged. More studies are needed in order to use the effects of HBOT on anterior segment morphology and on intraocular pressure for situations like glaucoma, corneal edema etc.

\section{Introduction}

Cornea endothelium plays an important role on regulation of stromal hydration and thus maintaining clarity of the cornea. During contact lens exposure reduced oxygen permeability on corneal epithelium causes increased hydration and stromal acidosis and an increase on central corneal thickness (CCT) [1]. The change in corneal structure causes refractive error and a decrease on visual acuity. Environmental factors may alter corneal structure. Only hypoxia and altitude exposure are shown to increase the corneal thickness [2]. Effects of hyperoxia on intraocular pressure (IOP) are explored in human and animal studies [3]. It has been reported that normobaric oxygen causes a decrease on IOP [4]. The effects of hyperbaric hyperoxia on IOP is open for research. Hyperbaric Oxygen Therapy (HBOT) is breathing \%100 oxygen under pressures over 1 atmospheres absolute (ATA). Breathing \%100 oxygen under 2.4 ATA creates a partial oxygen (PO2) pressure of $1900 \mathrm{mmHg}$ in the blood. This PO2 values increase the oxygen concentration dissolved in the blood thus delivering more oxygen for the tissues [6]; this has favorable 
effects for many diseases with an underlying pathophysiology of hypoxia. The changes in IOP and anterior segment after patients breath \%100 oxygen in a routine HBOT remains unclear. In this study the changes in IOP and anterior segment parameters are evaluated on patients with no anterior segment problems whom receive HBOT under 2.4 ATA for different indications.

\section{Materials And Methods}

The study was conducted in Konya Training and Research Hospital Department of Underwater and Hyperbaric Oxygen Treatment Center and Konya Training and Research Hospital Ophtalmology Clinic with ethical council approval (Selçuklu University Medical Faculty Non-invasive Clinical Researches Ethical Council 03.01.2018). In this study 30 patients with no anterior segment diseases who took Hyperbaric Oxygen Therapy (HBOT) in Konya Training and Research Hospital for various indications between the dates October 2017-October 2018 participated. All patients were evaluated by an ophthalmology technician (who is blinded for the study) before HBOT and 24 hours after a session of HBOT for the following parameters: refractive errors by an autorefractometer (Nidek, JAPAN), intraocular pressure by a pneumatic tonometer (Canon, JAPAN), anterior segment parameters pachymetry, keratometry, anterior chamber depth and iridocorneal angle values by a corneal topography (Pentacam, OCULUS, GERMANY). Patients with previous ocular surgery or trauma history, patients with ocular diseases like glaucoma or cataracts, patients with systemic diseases like hypertension, diabetes mellitus, patients with a history of smoking or alcohol abuse, patients under the age of 18 or over 80 were not included in the study. HBOT was applied in Konya Training and Research Hospital Underwater and Hyperbaric Oxygen Therapy Center in a $12+2$ multiplace chamber. Therapies were applied under 2,4 ATA pressure for 120 mins per session. Therapies were applied with pressurization to 45 feet in 20 minutes, 3 periods of breathing \%100 oxygen with a mask for 25 minutes, 2 air breaks of 5 minutes between 3 periods and an ascend in 15 minutes. Since there is a diurnal rhythm of IOP, the measurements were made at the same hours of the day, 10.00 in the morning. 6 simultaneous measurements were made for each patient and the mean value was evaluated for the IOP of the patient. If the standard deviation for 6 measurements is over $2 \mathrm{mmHg}$ patients were evaluated for another measurement. Refractive values were measured with an autorefractometry. 3 measurements were made for each patient and the mean value of the measurements were evaluated. For the pachymetry value topographic pupil centered corneal thickness value was taken as the criteria. Since there is a diurnal rhythm of IOP, the measurements were made at the same hours of the day, 10.00 in the morning. 6 simultaneous measurements were made for each patient and the mean value was evaluated for the IOP of the patient. If the standard deviation for 6 measurements is over $2 \mathrm{mmHg}$ patients were evaluated for another measurement. Refractive values were measured with an autorefractometry. 3 measurements were made for each patient and the mean value of the measurements were evaluated. For the pachymetry value topographic pupil centered corneal thickness value was taken as the criteria.

\section{Results}


In this study 30 eyes from a total of 30 patients were evaluated; 19 men (\%64) and 11 women (\%36). From the patients involved in the study; 17 patients (\%57) took HBOT for sudden hearing loss, 7 patients (\%23) took HBOT for chronic osteomyelitis, 4 patients (\%13) took HBOT for retinal artery occlusion, and 2 patients (\%7) took HBOT for avascular necrosis. Anterior segment structure and fundus examinations were evaluated normal except patients with retinal artery occlusion. For the patients with retinal artery occlusion normal eyes were included in the study. Changes in parameters before and after HBOT are presented in Table-1.

\section{Discussion}

Hyperbaric Oxygen Therapy is a treatment method applied as breathing $\% 100$ oxygen under pressures above 1 absolute atmospheres (ATA) [5]. It increases the oxygen concentration dissolved in the plasma thus maintain increased delivery for the tissues [6]. This effect is profitable in many diseases with hypoxia being the underlying pathophysiology [7]. Hyperbaric Oxygen Therapy is used as a primary indication for this purpose in ophthalmology in retinal arterial occlusions, central retinal vein occlusions, vascular originated cystoid macular edemas like retinal vein branch occlusions, scleral necrosis cases, orbital infections with mycotic and anaerobic origin, non-healing corneal edema and anterior segment ischemia. It can be used as an adjuvant therapy for proliferative vitreoretinopathy due to cycle cell anemia, primary open angle glaucoma, visual area defects following macular hole surgery and optic neuropathies with vascular origin [8]. There are limited number of studies on how hyperbaric oxygen therapy effects intraocular pressure and anterior segment parameters. Gallin-Cohen et al. reported a decrease in IOP in measurements after breathing air under 3 ATA and 1 ATA pressure [4]. Kalthoff and John reported a mean 2-3 mmHg decrease in IOP in a chamber pressurized to 2 and 4 ATA [9].

Hosking et al. studied the changes in IOP following induced hypercapnia and hyperoxia and observed a decrease in IOP values in hyperoxia in both normal people and patients with glacouma [20]. Bojic et al. reported that HBOT (Breathing \%100 02 under 2 ATA) do not effect IOP level in patients with glaucoma [10]. In this study IOP values were determined at 10.00 am before and after HBOT to minimize the error due to diurnal rhythm. A statistictically significant decrease in IOP values was observed after breathing air under 2,4 ATA pressure. The mechanism on how HBOT decreases IOP is unclear. Nevertheless it was submitted that the IOP decrease is due to the choroidal volume decrement which happens after a $\% 40$ reduction in intraocular fluid volume and a $3 \mathrm{mmHg}$ decrease in episcleral pressure after the partial oxygen pressure increase with HBOT [4]. In another opinion it was advocated that the increased oxygen concentration [4] and decreased $\mathrm{CO} 2$ concentration [11] are responsible for the decrease in IOP. In a study by Marcus et al. the increased partial $\mathrm{CO} 2$ pressure during exercise was reported to cause a decrease in blood $\mathrm{pH}$ and a simulataneous drop in IOP[11]. Increase in $\mathrm{H}+$ ions and low $\mathrm{pH}$ was reported among the known effects of HBOT [6]. Thus the active transport mechanism that plays an important role in aqueous humour production is inhibited by the increase in $\mathrm{H}+$ ions. This may decrease the aqueous humour production and thus cause a decrease in IOP. 
The number of studies on the effects of HBOT on central corneal thickness is limited. Ali Ayata et al. demonstrated a statistically significant decrease in central corneal thickness in non-diabetic patients taking HBOT [12]. Knut Evanger et al. reported that HBOT causes a decrease in both peripheral and central corneal thickness. This decriment was more prominent in peripheral cornea than the central. But the observed decriment was not statistically significant [13]. In another study by Evanger et al. no statistically significant change in central corneal thickness was observed in neither groups of phakic and pseudophakic patients after HBOT[14]. In this study a statistically significant decrease in the central corneal thickness was demonstrated. The underlying mechanism causing a decrease in central corneal thickness is unclear. There no blood vessels in the cornea. It absorbs the oxygen richly from the atmosphere and from the aqueous humour filling the anterior chamber [15]. Fluid and nutrients are slowly dispersed from the tears and the anterior chamber to corneal stroma [15]. Thin endothelial layer forms the deepest layer of the cornea and these cells pumps excess fluid from the stroma towards the anterior chamber to maintain the clarity of the cornea. The endothelial pump function is an energy focused process. HBOT induced hyperoxia may increase corneal metabolism and endothelial pump function. This may explain the changes in corneal thickness observed in our patients.

There are many studies about refractive changes after HBOT. A transient myopic shift is a defined situation in patients taking HBOT [16]. The reason for the refractive change demonstrated in earlier studies about this is the changes in crystalline lens. In a study a transient myopic shift was demonstrated in phakic patients while no change was observed in pseudophakic patients [14]. Myopic shift returns to previous state approximately 10 weeks following the treatment [17]. This should be taken into consideration in patients taking HBOT with a scheduled refractive surgery. No statistically significant changes were observed in this study in refractive measures of keratometry and spheric equivalent values of the patients.

The number of studies on the effects of HBOT on anterior chamber depth is limited. Knut Evanger at al. reported an increase in anterior chamber depth in phakic patients receiving HBOT while no statistically significant changes were observed in pseudophakic patients [14]. In another study by same authors no statistically significant changes were observed in a total number of 20 patients ( 10 men and 10 women) after 19 sessions of HBOT [19]. In our study a statistically significant decrease was observed in anterior chamber depths of 30 patients after HBOT when compared to values before HBOT. HBOT may be causing a decriment in anterior chamber depth secondary to its effects on aqueous humour [6]. Our study demonstrates the changes after one session of HBOT, while the mentioned studies reports the changes after longer durations of HBOT therapies; this may be the reason why our results are different from the results in the literature.

In conclusion; the acute effects of hyperbaric oxygen on anterior segment morphology and on intraocular pressure were evaluated in this study and a statistically significant decrease in central corneal thickness, intraocular pressure and iridocorneal angle values is demonstrated after one session of HBOT. No difference was observed in refractive error and keratometric values of the patients. These findings of 
changes stimulated by HBOT on anterior segment morphology and on intraocular pressure should be supported with more studies with larger groups and longer follow-up durations.

\section{Declarations}

\section{STATEMENT OF ETHICS}

Participants were given written information detailing the study. The study received approval from the local ethics committee (Selçuklu University Medical Faculty Non-invasive Clinical Researches Ethical Council 03.01.2018) and was conducted in accordance with the tenets of the Declaration of Helsinki. Local ethics committee decision number is $2018 / 12$. Informed consent was obtained from all participants.

\section{CONFLICT OF INTEREST STATEMENT AND FUNDING SOURCES}

The authors have no conflicts of interest to declare. There is no fund or sponsor of the study.

\section{AUTHOR CONTRIBUTIONS}

Fatih Akıncı and Muammer Özcımen conceived the original idea. Abdullah Arslan supervised the study. Fatih Akıncı wrote the manuscript with support Muammer Ozcimen. All authors discussed the results and contributed to the final manuscript.

\section{References}

1. Bonanno J, Poise K: Corneal acidosis during contact lens wear: effects of hypoxia and carbon dioxide. Invest Ophthalmol Vis Sci 1987; 28: 1514-1515.

2. Stickel TE, Bonanno JA: The relationship between corneal oxygen tension and hypoxic corneal edema. Optometry 2002; 73: 598- 604.

3. Anderson B. Jr. Ocular effects of changes in oxygen and carbon dioxide tension. Trans Am Opthalmol Soc 1968; 66:423-74.

4. Gallin-Cohen PF, Podos SM, Yablonski ME. Oxygen lowers intraocular pressure. Ophthalmol Vis Sci 1980; 43-48

5. Feldmeier, JJ. Definition of $\mathrm{HBO}^{2}$ In: Feldmeier JJ (ed). Hyperbaric Oxygen 2003: Indications and Results: The Hyperbaric Oxygen Committee Report. Kensington, MD: Undersea and Hyperbaric Medical Society, 2003: 1-2.

6. Hammarlund, C. The physiologic effects of hyperbaric oxygenation. In: Kindwall EP, Whelan HT. eds. Hyperbaric Medicine Practice, 2nd rev ed. USA: Best Publishing Com. 2002: 37-69 
7. Jain KK: $\mathrm{HBO}^{2}$ in Opthalmology. In: Textbook of Hyperbaric Medicine, 4th revised edition Jain KK ed. Seattle-Toronto-Bern-Göttingen: Hogrefe \& Huber Publishers 2004: 383-392

8. Oguz Halıt, Gungor Sobacı.The Use of Hyperbaric Oxygen Therapy in Ophtalmology.Surv. Ophtalmolology 53:112-120, 2008

9. Kalthoff H, John S, Scholz V. Problems of intraocular pressure in scuba diving. Klin Monatsbl Augenheilkd. 1975; 166 : 488-493.

10. Bojic L, Racic G, Gosovic S, Kovacevic H. The effect of hyperbaric oxygen breathing on the visual field in glaucoma. Acta Ophthalmol 1993; 71:315-319.

11. Marcus DF, Krupin T, Podos SM, Becker B. The effect of exercise on intraocular pressure. I. Human beings. Invest Ophthalmol 1970; $9:$ 749-752.

12. Ayata A, Uzun G, Mutluoglu M, Unal M, Yıldız S, Ersanlı D. İnfluence of Hyperbaric Oxygen Therapy on Central Corneal Thickness Ophtalmic Research 2012;47:19-22

13. Evanger Vaagbo G, Thorsen E, Haugen OH. Central and Periferal Corneal Thickness in Patients During Hyperbaric Oxygen Therapy.Investigative Ophtalmology and Visuel Science March 2012 ,Vol.53,126

14. Evanger K Vaagbo G, Thorsen E, Haugen OH. Phakic and Pseudophakic Eyes in Patients During Hyperbaric Oxygen Therapy, Optometry and Vision Science, Vol. 88, No. 6, June 2011

15. Remington LA: Cornea and sclera; in Remington LA (ed): Clinical Anatomy of the Visual System. Oxford, Elsevier, 2005, pp 23.

16. Lyne AJ. Ocular effects of hyperbaric oxygen. Trans Ophthalmol Soc UK. 1978 April;98(1):66-68.

17. Evanger $\mathrm{K}$, Haugen $\mathrm{OH}$, Irgens $\AA$, Aanderud L, Thorsen E. Ocular refractive changes in patients receiving hyperbaric oxygen administered by oronasal mask or hood. Acta Ophthalmol. Scand. 2004: 82: $449-453$

18. Evanger K, Pierscionek BK, Vaagbø G, Thorsen E, Haugen OH. Myopic Shift during Hyperbaric Oxygenation Attributed to Lens Index Changes. Optom Vis Sci.2015;92(11):1076-84

19. Fledelius Hans $C$, Jansen EC, Thorn J . Refractive change during hyperbaric oxygen therapy. A clinical trial including ultrasound oculometry. Acta Ophthalmol Scand.2002;80(2):188-90

20. Hosking SL, Harris A, Chung HS, Jonescu-Cuypers CP, Kagemann L, Roff Hilton E et al. Ocular hemodynamic responses to induced hypercapnia and hyperoxia in glaucoma. $\mathrm{Br} \mathrm{J}$ Opthalmol 2004; 88: $406-411$

\section{Table}

Table 1 is not available in this version of the manuscript. 